\title{
Hydrogen Bond Stabilization in Diels-Alder Transition States. The Cycloaddition of hydroxy-ortho-quinodimethane with Fumaric acid and Dimethylfumarate
}

\author{
V. Tamilmani, C. A. Daul, J. Lage Robles, and C. G. Bochet* \\ Department of Chemistry, \\ University of Fribourg, \\ CH-1700 Fribourg, Switzerland \\ P. Venuvanalingam \\ Department of Chemistry, \\ Bharathidasan University, \\ Tiruchirappalli-620 024, \\ Tamil Nadu, India
}

(Dated: February 25, 2005)

\begin{abstract}
DFT investigations on the mechanism of Diels-Alder reactions of a hydroxy-orthoquinodimethane with fumaric acid derivatives were performed to understand the origin of the syn or anti configuration of the adducts. The diene hydroxyl group and the dienophile carboxyl group show hydrogen bonding in the transition state, significantly favouring the syn product. This reaction is poorly diastereoselective for $\mathrm{R}=\mathrm{CO}_{2} \mathrm{Me}$ (ratio syn/anti $=57: 43$ ) and significantly improved for $\mathrm{R}=\mathrm{CO}_{2} \mathrm{H}$ (ratio syn/anti $=71: 29$ ). The stereoselectivities are properly predicted from transition structures calculated at B3LYP/6-31G(d) level of approximation.
\end{abstract}

Keywords: Diels-Alder, DFT, stereoselectivity, Transition states, ortho-quinodimethane 


\section{INTRODUCTION}

The photochemical excitation of ortho-tolualdehyde is well known to generate a highly reactive ortho-quinodimethane (QDM) type intermediate, readily trapped by an alkene in a Diels-Alder reaction. This process is an efficient way to assemble a dihydronaphthalene skeleton bearing three contiguous chiral centers. The cycloaddition could, in principle, lead to two enantiomeric pairs of diastereomers, as seen in Fig 1.

The Diels-Alder reactions are amongst the most useful and versatile in organic synthesis, for their remarkable stereoselectivity[1-4] and atom economy[5]. Inter [6-8] and intramolecular $[9,10]$ Diels-Alder reactions are well documented and they have been investigated both experimentally and theoretically [11-14]. Further, there are many reports of catalysts [1517] and solvents [18] impacting upon the rates and stereoselectivities of Diels-Alder reactions through various interactions including hydrogen bonding. Gain or loss of aromaticity also plays an important role in Diels-Alder transition states and adducts[19]. In the photochemically assisted cycloaddition of $\mathbf{2}$ with $\mathbf{3}$, we noticed an interesting change in the product distribution when switching from fumaric acid (FA) $\mathbf{3 a}$ (ratio $\mathbf{4 a} / \mathbf{5 a}=71: 29$ ) to dimethyl fumarate $(\mathrm{DMF}) \mathbf{3} \mathbf{b}$ (ratio $\mathbf{4 b} / \mathbf{5 b}=57: 43)[20]$. The goal of the present work is to rationalize this observation computationally, and to understand the factors controlling the stereospecificity and, in particular, the influence of hydrogen bonding on the endo vs exo transition states (TS).

\section{COMPUTATIONAL DETAILS}

DFT calculations were carried out using Gaussian03, Revision B.01 and C.01 [21], transition states have been located using Berny's algorithm [22]. All calculations were carried out on a cluster of AMD Opteron(tm) Processors 246, 2.0 GHz CPU. The hybrid B3LYP functional-Becke's three parameter exchange functional (B3) [23, 24] with the non-local correlational functional of Lee, Yang and Parr (LYP)[25] and a 6-31G(d) basis set was used throughout. Stationary points that were located have been characterized by computing the vibrational frequencies. In all cases reactants and products had real frequencies and the transition states had a single imaginary frequency. Furthermore TSs have been confirmed by animating the imaginary frequency in MOLDEN[26]. After locating a TS, intrinsic reaction 
coordinate (IRC) [27] calculations were also carried out along the corresponding Minimal Energy Path (MEP) in order to identify its respective reactant and product. Bond orders (BO) were calculated as the Wiberg [28] indices which are derived from the natural atomic orbitals analysis, and from them bond formation index $B F_{i}$ or bond cleavage index $B C_{j}$ have been calculated as described below [29, 30]:

$$
\begin{gathered}
B F_{i} \text { or } B C_{j}=\frac{B O_{i}^{T S}-B O_{i}^{R}}{B O_{i}^{P}-B O_{i}^{R}} \times 100 \\
B F_{\text {Ave }}=\frac{1}{n} \sum_{i=1}^{n} B F_{i}
\end{gathered}
$$

where the summation is over the "forming bonds."

$$
B C_{\text {Ave }}=\frac{1}{n} \sum_{i=1}^{n} B C_{i}
$$

where the summation is over the "cleaving bonds."

Bond formation-cleavage average $\left(B F C_{A v e}\right)$ values have been calculated as

$$
B F C_{A v e}=\frac{1}{2}\left(B F_{A v e}+B C_{A v e}\right)
$$

\section{RESULTS AND DISCUSSION}

\section{Reactions of ortho-QDM with FA and DMF}

ortho-QDM undergoes Diels-Alder reaction with FA and DMF to form the diastereomeric syn/anti adducts, depending on the relative orientation of the reactants (Fig.2). The substituent on the dieneophile may be directed away from the diene (exo approaches A and C) or towards the diene (endo approaches $\mathrm{B}$ and $\mathrm{D}$ ) with respect to the $\mathrm{OH}$ group. A careful consideration of the dieneophile structure reveals that it has three types of conformations as described in Fig. 3: namely $S$-cis $/ S$-cis, $S$-cis/S-trans, $S$-trans $/ S$-trans in which the $S$-cis $/ S$ cis conformation was calculated as the most stable one. Hence, we have investigated all the possible approaches(A-D) for the reactions of ortho-QDM with FA and DMF with the $S$-cis/S-cis conformation. In addition, the favourable exo approach C has been investigated for all other conformations. The $S$-trans/S-cis conformation can react with the diene in 
two possible ways; either with the cis or trans part of the dieneophile leaning towards the $\mathrm{OH}$ termination of the diene. One important point to be mentioned here, is that we have two types of dienes with $\mathrm{OH}$ groups outside the ring and inside the ring. The calculation shows that the diene with the $\mathrm{OH}$ group inside $((Z)$-enol) is more stable than its isomer with the $\mathrm{OH}$ outside $((E)$-enol) and that the exo approach $\mathrm{C}$ is kinetically favored. However, it has been established experimentally that this isomer has a very short lifetime by way of quantum tunneling [31]. As a consequence, we considered only the isomer with the $\mathrm{OH}$ outside as experimentally relevant. Hence, the application of the Arrhenius equation [33] to the activation energy differences for approaches $A$ and $B$ predicts the ratios $4 \mathbf{4} / 5 \mathbf{a}$ $=85: 15(0.6 \mathrm{kcal} / \mathrm{mol})$ and $4 \mathrm{~b} / 5 \mathrm{~b}=70: 30(0.52 \mathrm{kcal} / \mathrm{mol})$, in accordance to the trend observed experimentally. The rate of a chemical reaction is often sensitive to the nature of the solvent. However, rates of pericyclic reactions are not very sensitive to solvents [32]. This insensitivity is related to the mechanism of this type of reaction because there is little charge development in the reacting system during the activation process. We have therefore omitted the solvent effect in our calculations.

\section{Transition state geometry}

The reactions were found to occur in a concerted fashion, through an asynchronous transition state due to the asymmetrical nature of the diene. The terminal carbon of the diene reacts first, as can be seen from the predicted bond lengths of the newly forming bonds in the TSs (Fig. 4) as compared to the hydroxy terminal carbon. This is due to the fact that the charges on the terminal carbon and hydroxy terminal carbon are -0.461 and 0.009 respectively, which clearly indicates the increased nucleophilicity of the former compared to the latter one. The twist angles are high in exo TSs as can be seen from Table I. Also hydrogen bonding is present in them. The bond distance between $\mathrm{O}$ and $\mathrm{H}$ is $1.675 \AA$ for FA and $1.680 \AA$ for DMF. The bond angles (OHO) are 148.83, 149.29 degrees respectively.

\section{Energetics}

The FOE (frontier orbital energy) gaps presented in Table I suggest that these reactions are "normal electron demand" cycloadditions meaning that the electrons move from the 
HOMO of the diene to the LUMO of the dieneophile. The negative reaction energy values for these reaction is characteristic of an exothermic reaction. The activation energies presented in Table I reveal that $S$-cis/S-cis TS C is kinetically more favorable, both for FA and DMF when compared to all the other three pathways (Fig. 5). Moreover, this reaction path shows an intramolecular hydrogen bond interaction between the dieneophile oxygen and the proton from the hydroxyl group in the diene of OH. For $\mathrm{R}=\mathrm{CO}_{2} \mathrm{H}$ (series a) the activation energy of the exo approach $\mathrm{C}$ is $0.77 \mathrm{kcal} / \mathrm{mol}$, whereas the exo approach $\mathrm{A}$ has an activation energy of $3.21 \mathrm{kcal} / \mathrm{mol}$. Furthermore, the stereoselectivity decreases for $\mathrm{R}=\mathrm{CO}_{2} \mathrm{Me}$. In that case, the activation energy of the exo approach $\mathrm{C} 2.31 \mathrm{kcal} / \mathrm{mol}$ and the exo approach A $3.99 \mathrm{kcal} / \mathrm{mol}$. For both series, the exo approach $\mathrm{C}$ is kinetically more favored. The stereoselectivity depends on the kinetic control of the reaction. During this reaction, the ring becomes partially aromatic in the TS and this results in considerable stabilization of the TS. Owing to this extra stabilization, the activation energy is significantly lowered. The ring becomes fully aromatic in the product and this gain in aromaticity from the TS to the product makes the reaction highly exothermic.

\section{Bond order analysis}

Based on the bond order analysis, the $B C_{j}, B F_{i}$ and $B F C_{A v e}$ values are presented in Table II. The developing $C_{5}-C_{6} \pi$ bond is more pronounced than the $C_{8}-C_{11}$ and $C_{10}-C_{7}$ $\sigma$ bonds. This shows that the ring starts to gain aromaticity in the TS itself. In this reaction, the diene cleaves $\left(C_{7}-C_{5}, C_{6}-C_{8}, C_{11}-C_{10}\right)$ to a higher extent than the newly forming bond $\left(C_{5}-C_{6}, C_{8}-C_{11}, C_{10}-C_{7}\right)$. The relatively low $B F C_{A v e}$ values indicate that the transition states are early transition states. Hydrogen bond is forming between the hydroxyl proton and dieneophile oxygen. The bond order of hydrogen bonds in the TSs for the reaction with FA and DMF are $0.0975,0.0955$ respectively.

\section{CONCLUSIONS}

We have theoretically investigated a reaction, the cycloaddition between ortho-QDM with FA and DMF using DFT, the B3LYP functional and a 6-31G(d) basis set. Our results reveal that the quasi-absence of diastereoselectivity for the reaction with $\mathrm{R}=\mathrm{CO}_{2} \mathrm{Me}$ (ratio 
$\mathbf{4 b} / \mathbf{5 b}=57: 43)$ becomes modest with $R=\mathrm{CO}_{2} H($ ratio $\mathbf{4 a} / \mathbf{5 a}=71: 29)$ which is in good agreement with experiment and that the exo approach is kinetically more favored over the endo, for both FA and DMF. Due to the hydrogen bond stabilization and gain of aromaticity the activation energy barriers are very low. These stereoselectivities are correctly predicted from transition structures. Computed energy barrier explains very well the experimental stereoselectiyity of the reaction. Bond order analysis shows clearly the formation of the new bonds and the cleavage of the reacting double bonds

\section{ACKNOWLEDGEMENT}

This work was supported by the Swiss National Science Foundation and V.T thanks to "Federal Commission for Scholarships for Foreign Students" (FCS) for financial assistance. 
FIG. 1: Reaction of ortho-tolualdehyde.

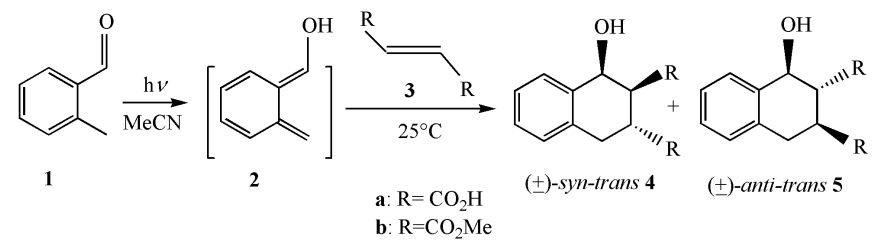


FIG. 2: Possible approaches for the reaction of ortho-hydroxy quinodimethane.

$$
\begin{aligned}
& \frac{e x o}{\mathrm{~A}} \\
& \text { exo }
\end{aligned}
$$



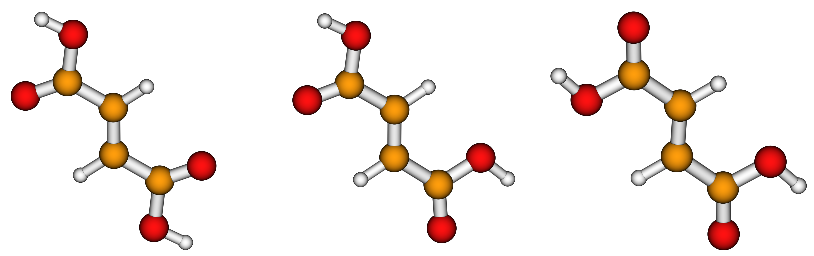

S-cis $/ \mathrm{S}$-cis $=0.0 \mathrm{kcal} / \mathrm{mol}$

S-cis $/$ S-trans $=0.57 \mathrm{kcal} / \mathrm{mol}$

$\mathrm{S}$-trans $/ \mathrm{S}$-trans $=0.58 \mathrm{kcal} / \mathrm{mol}$

FIG. 3: Possible conformations of Fumaric acid. 

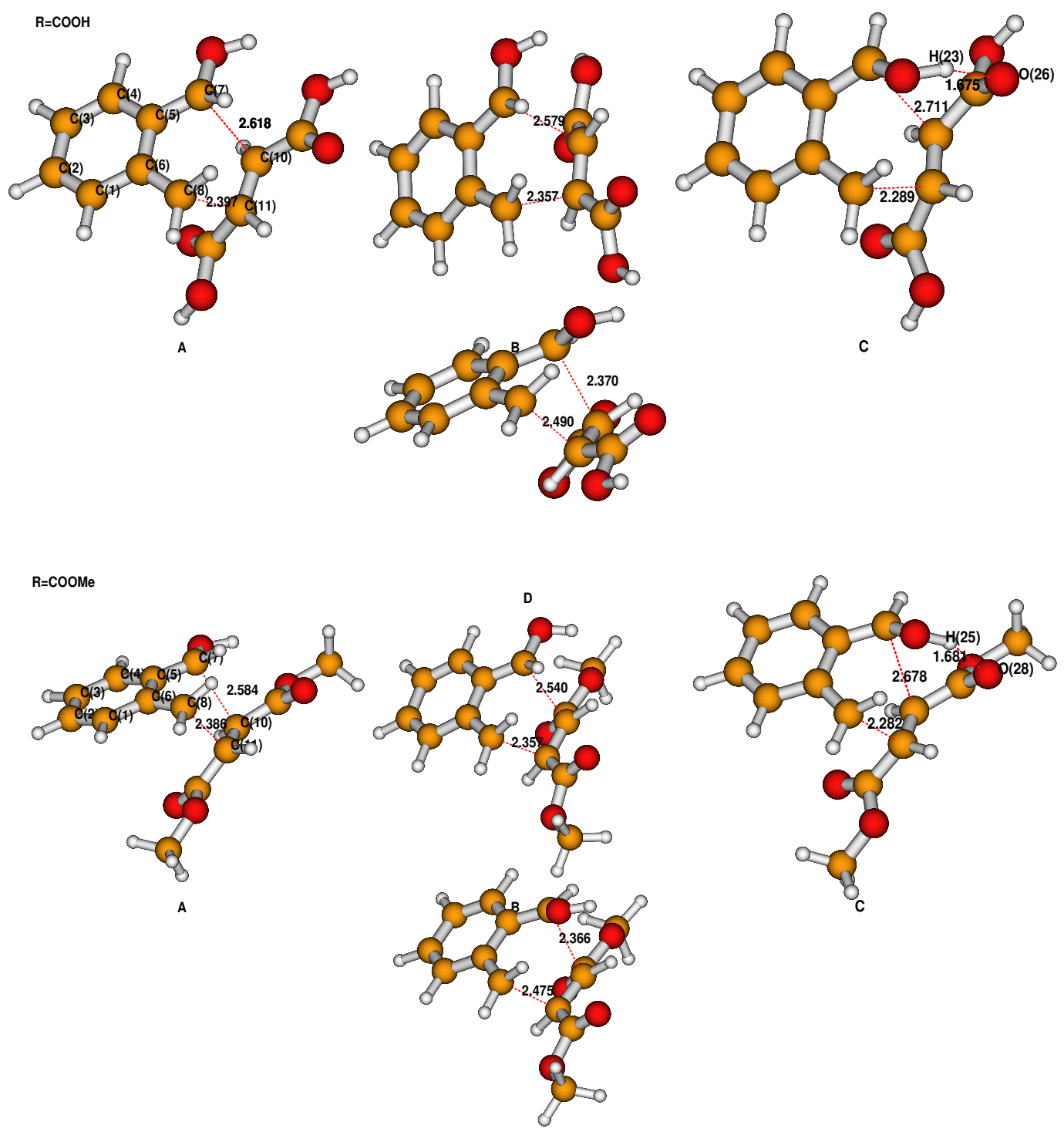

FIG. 4: Optimized Transition State Geometries. 


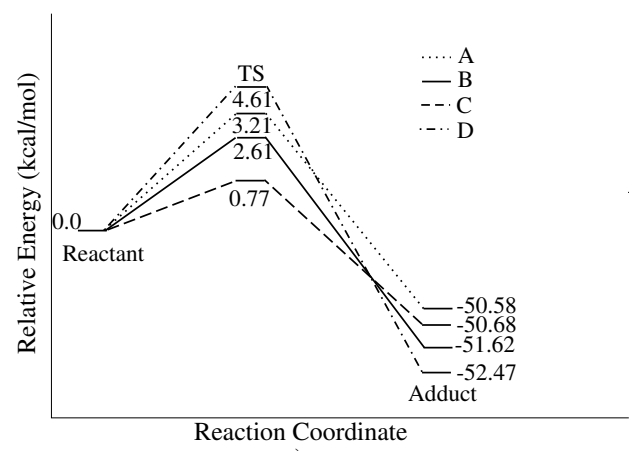

a)

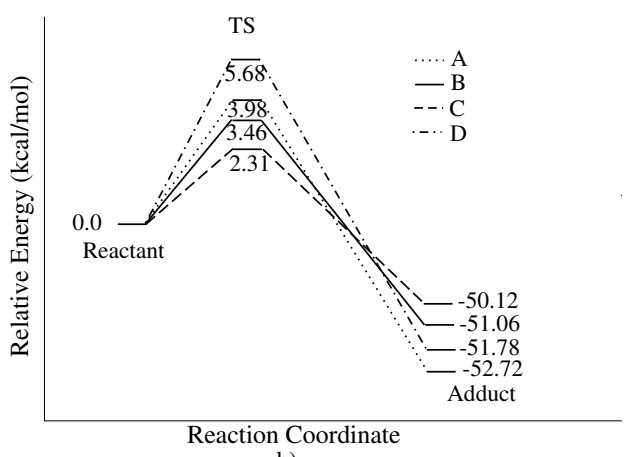

b)

FIG. 5: Schematic energy diagrams for a) $\mathrm{R}=\mathrm{CO}_{2} \mathrm{H}$ and b) $\mathrm{R}=\mathrm{CO}_{2} \mathrm{Me}$. 
TABLE I: Calculated Activation, Reaction energies (kcal/mol), twist angle (degrees), $\nu\left(\mathrm{cm}^{-1}\right)$ and Frontier orbital energy gaps $(\mathrm{eV})$.

\begin{tabular}{|c|c|c|c|c|c|c|c|c|}
\hline Substrate & Conformation & Approach & $\Delta E^{\neq a}$ & $\Delta E_{r}^{a}$ & Twist angle & $\nu$ & $\Delta E_{1}^{b}$ & $\Delta E_{2}^{c}$ \\
\hline \multirow[t]{7}{*}{$\mathrm{R}=\mathrm{COOH}$} & \multirow[t]{4}{*}{ S-cis/S-cis } & $\mathrm{A}$ & 3.21 & -50.58 & -7.83 & -229.98 & 0.08 & 0.24 \\
\hline & & B & 2.16 & -51.62 & 0.50 & -284.96 & 0.08 & 0.24 \\
\hline & & $\mathrm{C}$ & 0.77 & -50.68 & 19.90 & -295.61 & 0.08 & 0.24 \\
\hline & & $\mathrm{D}$ & 4.61 & -52.47 & 22.35 & -330.66 & 0.08 & 0.24 \\
\hline & S-cis/S-trans & $\mathrm{C}$ & 1.08 & -53.02 & 13.48 & -302.60 & 0.09 & 0.29 \\
\hline & S-trans/S-trans & $\mathrm{C}$ & 5.78 & -50.58 & -17.73 & -372.90 & 0.09 & 0.29 \\
\hline & S-trans/S-cis & $\mathrm{C}$ & 5.75 & -52.58 & -17.75 & -365.59 & 0.09 & 0.29 \\
\hline \multirow[t]{7}{*}{$\mathrm{R}=\mathrm{COOMe}$} & \multirow[t]{4}{*}{ S-cis/S-cis } & $\mathrm{A}$ & 3.98 & -52.72 & -8.51 & -254.62 & 0.08 & 0.28 \\
\hline & & B & 3.46 & -51.06 & 5.13 & -302.75 & 0.08 & 0.28 \\
\hline & & $\mathrm{C}$ & 2.31 & -50.12 & 18.95 & -312.55 & 0.08 & 0.28 \\
\hline & & $\mathrm{D}$ & 5.68 & -51.78 & 19.09 & -345.25 & 0.08 & 0.28 \\
\hline & S-cis/S-trans & $\mathrm{C}$ & 2.35 & -54.50 & 22.99 & -320.13 & 0.09 & 0.23 \\
\hline & S-trans/S-trans & $\mathrm{C}$ & 7.04 & -52.59 & -18.14 & -382.87 & 0.07 & 0.23 \\
\hline & S-trans/S-cis & $\mathrm{C}$ & 6.73 & -52.12 & -18.42 & -381.39 & 0.09 & 0.23 \\
\hline
\end{tabular}

$a_{\text {zero-point energy corrected }}$

${ }^{b} E_{\text {HOMO }}($ Diene $)-E_{L U M O}($ Dieneophile $)$

${ }^{c} E_{\text {HOMO }}($ Dieneophile $)-E_{L U M O}($ Diene $)$ 
TABLE II: Percentage of bond formation and cleavage in the TS.

\begin{tabular}{|c|c|c|c|c|c|c|c|c|c|}
\hline \multirow[b]{2}{*}{ Substrate } & \multirow[b]{2}{*}{ Conformation } & \multirow[b]{2}{*}{ Approach } & \multicolumn{3}{|c|}{$B F_{i}$} & \multicolumn{3}{|c|}{$B C_{j}$} & \multirow[t]{2}{*}{$B F C_{A v e}$} \\
\hline & & & $C_{5}-C_{6}$ & $C_{8}-C_{11}$ & $C_{10}-C_{7}$ & $C_{7}-C_{5}$ & $C_{6}-C_{8}$ & $C_{11}-C_{10}$ & \\
\hline \multirow[t]{7}{*}{$\mathrm{R}=\mathrm{COOH}$} & S-cis/S-cis & $\mathrm{A}$ & 29.75 & 26.24 & 19.16 & 32.11 & 37.37 & 38.35 & 31.75 \\
\hline & & B & 32.64 & 29.02 & 18.67 & 34.14 & 39.98 & 39.66 & 32.36 \\
\hline & & $\mathrm{C}$ & 34.85 & 33.90 & 15.64 & 39.14 & 47.26 & 46.71 & 36.25 \\
\hline & & $\mathrm{D}$ & 34.49 & 26.77 & 26.78 & 42.63 & 38.34 & 43.38 & 35.40 \\
\hline & S-cis/S-trans & $\mathrm{C}$ & 36.12 & 33.87 & 15.33 & 38.61 & 47.51 & 45.19 & 36.11 \\
\hline & S-trans/S-trans & $\mathrm{C}$ & 35.85 & 39.88 & 17.48 & 36.13 & 51.78 & 48.31 & 38.24 \\
\hline & S-trans/S-cis & $\mathrm{C}$ & 35.74 & 53.26 & 48.88 & 35.74 & 53.26 & 48.88 & 38.58 \\
\hline \multirow[t]{7}{*}{$\mathrm{R}=\mathrm{COOMe}$} & S-cis/S-cis & $\mathrm{A}$ & 30.54 & 27.03 & 17.38 & 32.61 & 37.89 & 38.53 & 30.66 \\
\hline & & $\mathrm{B}$ & 33.38 & 29.29 & 19.89 & 35.08 & 40.00 & 39.76 & 32.90 \\
\hline & & $\mathrm{C}$ & 36.36 & 34.32 & 16.89 & 39.37 & 47.25 & 45.99 & 43.26 \\
\hline & & $\mathrm{D}$ & 35.03 & 27.32 & 27.18 & 42.76 & 38.71 & 43.02 & 35.67 \\
\hline & S-cis/S-trans & $\mathrm{C}$ & 33.61 & 34.15 & 16.13 & 38.80 & 47.34 & 44.61 & 44.24 \\
\hline & S-trans/S-trans & $\mathrm{C}$ & 36.55 & 40.28 & 17.93 & 36.72 & 51.68 & 47.84 & 38.50 \\
\hline & S-trans/S-cis & $\mathrm{C}$ & 36.11 & 41.27 & 17.62 & 36.24 & 52.57 & 47.70 & 44.63 \\
\hline
\end{tabular}


* Electronic address: Christian.Bochet@unifr.ch,Fax:+41263009738

[1] D. J. Tantillo, K. N. Houk, and M. E. Jung., J. Org. Chem. 66, 1938 (2001).

[2] D. Grée, L. Vallerie, R. Grée, L. Toupet, I. Washington, J. P. Pelicier, M. Villacampa, J. M. Perez, and K. N. Houk., J. Org. Chem. 66, 2374 (2001).

[3] S. M. Bakalova and A. G. Santos., J. Org. Chem. 69, 8475 (2004).

[4] M. F. Cheng and W. K. Li., Chem. Phys. Lett. 368, 630 (2003).

[5] B. M. Trost., Science. 254, 1471 (1991).

[6] E. J. Corey., Angew. Chem. Int. Ed. 41, 1650 (2002).

[7] C. O. Kappe, S. S. Murphree, and A. Padwa., Tetrahedron. 53, 14179 (1997).

[8] K. C. Nicoloau, S. A. Synder, T. Montagnon, and G. Vassilikogiannakis., Angew. Chem. Int. Ed. 41, 1668 (2002).

[9] B. R. Bear, S. M. Sparks, and K. J. Shea., Angew. Chem. Int. Ed. 40, 820 (2001).

[10] D. F. Taber, Intramolecular Diels-Alder and Alder Ene Reactions (Springer-Verlag, Berlin, 1984).

[11] S. Sakai., J. Phys. Chem. A. 104, 922 (2000).

[12] E. Goldstein, B. Beno, and K. N. Houk., J. Am. Chem. Soc. 118, 6036 (1996).

[13] E. Goldstein, B. R. Beno, and K. N. Houk., Theor. Chem. Acc. 103, 81 (1999).

[14] K. N. Houk, B. R. Beno, M. Nendel, K. Black, H. Y. Yoo, S. Wilsey, and J. K. Lee., THEOCHEM 398-399, 169 (1997).

[15] K. Ishihara, H. Kurihara, M. Matsumoto, and H. Yamamoto., J. Am. Chem. Soc. 120, 6920 (1998).

[16] T. Schuster, M. Kurz, and M. W. Goebel., J. Org. Chem. 65, 1697 (2000).

[17] E. J. Corey and T. W. Lee., Chem. Commun. p. 1321 (2001).

[18] Y. Huang and V. H. Rawal., J. Am. Chem. Soc. 124, 9662 (2002).

[19] M. Manoharan and P. Venuvanalingam., J. Phys. Org. Chem. 11, 133 (1998).

[20] J. Lage Robles and C. G. Bochet., Manuscript in Preparation. (2005).

[21] M. J. Frisch, G. W. Trucks, H. B. Schlegel, G. E. Scuseria, M. A. Robb, J. R. Cheeseman, J. A. Montgomery, J. T. Vreven, K. N. Kudin, J. C. Burant, et al., Gaussian 03, Gaussian (2004). 
[22] H. B. Schlegel., J. Comp. Chem. 3, 214 (1982).

[23] A. D. Becke., J. Chem. Phys. 98, 1372 (1993).

[24] A. D. Becke., J. Chem. Phys. 98, 5648 (1993).

[25] C. Lee, W. Yang, and R. G. Parr., Phys. Rev. B. 37, 785 (1988).

[26] G. Schaftenaar and J. H. Noordik., J. Comput. -Aided Mol. Design. 14, 123 (2000).

[27] K. Ishida, K. Morokuma, and A. Komornicki., J. Chem. Phy. 66, 2153 (1977).

[28] K. Wiberg., Tetrahedron. 24, 1083 (1968).

[29] M. Manoharan and P. Venuvanalingam., J. Mol. Struct. 394, 41 (1997).

[30] M. Manoharan and P. Venuvanalingam., J. Chem. Soc.; Perkin Trans. 2. (1997).

[31] J. Gebicki and T. Bally., Acc. Chem. Res. 30, 477 (1997).

[32] L. R. Domingo., J. Org. Chem. 66, 3211 (2001).

$[33] e^{-\Delta \Delta G^{\neq} / R T}$ 